Palestine Exploration Quarterly

\title{
A New Interpretation of the Phaestos Disk: the Oldest Music in the World?
}

\section{F. W. Read}

To cite this article: F. W. Read (1921) A New Interpretation of the Phaestos Disk: the Oldest Music in the World?, Palestine Exploration Quarterly, 53:1, 29-54, DOI: 10.1179/ peq.1921.53.1.29

To link to this article: http://dx.doi.org/10.1179/peq.1921.53.1.29

Published online: 02 Dec 2013.

Submit your article to this journal $\square$

Llll Article views: 7

Q View related articles ¿ 


\section{A NEW INTERPRETATION OF THE PHAESTOS DISK:}

\section{THE OLDEST MUSIC IN THE WORLD?}

By F. W. ReAD.

1. Introluction.-The unique and hitherto undeciphered document, known as the Phaestos Disk, was discovered by Dr. Pernier, the head of the Italian Mission, in the course of the excavations of 1908 on the site of the Palace of Phaestos on the south coast of Crete. According to the generally accepted chronology of Sir Arthur Evans, it belongs to the end of the Middle Minoan period (c. 1600 B.C.). It is a more or less circular piece of fine clay having a diameter of about 6 inches and a thickness varying from about $\frac{3}{5}$ to $\frac{4}{5}$ inch. Both faces are covered with signs impressed by means of stamps, each sign being absolutely identical in form at every occurrence. These signs are separated by a spiral and are divided into groups by vertical lines: there being 122 characters, making 31 groups, on Face A, and 119 characters, making 30 groups, on Face" B. The number of individual characters is 45 . The two faces of the Disk are shown in figs. 1 and 2, and the separate signs, with the method of denoting them devised by Prof. Macalister, in fig. 3.1 The tables at the end of the paper ${ }^{2}$ have been drawn up in this conventional notation, which it must be understood is merely a method of representing the signs without reproducing them, and is not intended to indicate any opinion as to their true value. The line drawn below the last sign of certain groups is indicated in the tables by underlining.

Such a well-preserved example of a wholly new script naturally attracted the attention of archaeologists immediately on its publication; but the hopes of a speedy decipherment have been disappointed, none of the suggestions made having obtained acceptance. As will be seen from the Bibliography, an active discussion was maintained till 1914 , when it was apparently brought to an end by the outbreak of war. The study was resumed in 1919 by the Australian scholar, Mr. A. Rowe, whose essay was noticed

1 These figures are printed from the blocks prepared for Prof. Macalister's The Philistines, by the kind permission of the Oxford University Press.

2 The tables are transcribed from those prepared by Mr. A. C. Bryant, B.A., to whom, and to Mr. E. J. Pilcher, the author is much indebted for advice and assistance; they are, however, in no way responsible for the opinions expressed. 
in the Quarterly Statement, April, 1920 (pp. 51, 65). This publication, together with the important excavations at Askalon, which may be expected to throw much light on the history of the Philistines, who were probably of Cretan origin, affords a suitable opportunity for reviewing the whole question. There was no intention, in the first instance, to do more than summarise the various opinions that have been expressed, and to indicate what appeared to be the strength and weakness of each ; but, as the study has led the writer to the quite unforeseen conclusion that the signs printed on the Disk are musical notes, a discussion of the evidence for this interpretation has been added to the review of the literature.

2. Direction of the Writing.-There are really three questions involved here: (1) the direction in which the spiral was traced; (2) the direction in which the characters were impressed; and (3) the direction in which the characters are to be read. We believe that Dr. Della Setal has demonstrated that in all three cases the direction is from the periphery to the centre, that is to say, from right to left.

(1) The general appearance of the two faces seems almost sufficient of itself to show that the scribe commenced to draw the spiral from the vertical line with five points. ${ }^{2}$ Dr. Della Seta contends that he drew the first portion on Face A with one sweep of the hand as far as the angle at A 12, and then started afresh in a new direction to avoid the row of signs near the periphery. Another clear indication is to be found in two places on Face B, where he has not at first got quite the right curve and has had to recommence his line. In both places (B 14, 30) the small piece of the spiral out of the proper course runs to the left. ${ }^{3} \mathrm{~A}$ third argument is provided by the differing shapes of the compartments in the centre of $A$ and $B$. On Face $A$ the spiral continues more or less regularly to the very last. On Face $B$ the final compartment is quite irregular, indeed, almost a triangle. The explanation obviously is that the scribe found that he had surplus space to dispose of at the end of his task on Face B, but not on Face A.

1 It has not been thought necessary to give references to the writers included in the Bibliography.

2 There is a slight inacouracy in the drawing, which showe four points only on Face $A$.

3 On all matters of detail reference should be made to Dr. Pernier's beautiful reproduction. 
(2) It can be equally (if not more) clearly shown that the characters were impressed from right to left. One of the large groups containing seven signs occurs twice, at A 17 and 29, but the first four signs are arranged differently in the two cases. In A 29 the second sign is placed over the first instead of by its side, and the third and fourth are upside down. Evidently the scribe saw that he had not sufficient space left to allow him to proceed in the orthodox manner. It will also be noticed that at $\mathrm{A} 12$, where the spiral begins to recede from the periphery, the signs, nevertheless, keep at about the same average distance from it. A glance at the illustration will show that, while this arrangement would be quite natural to a scribe who had been writing all round the periphery, it would hardly be followed by one who was approaching it from the centre. Finally, where a sign has slightly grazed or obliterated a portion of another sign, it is the sign to the right that has suffered. Thus, in A 14, 3 has cut away a small portion of 2 ; and in A 29, 3 has grazed 2, and 4 has cut off part of 3.

Against the above arguments one fact only can be urged, which, however, admits of a simple explanation. In A 4 and 5, not only are the signs crowded together, but 5,2 has very considerably damaged 5, 3, from which it may be argued that the scribe was getting near the end of his space, proceeding from left to right. But a careful examination of the photograph reveals that group 5 did not originally contain the present signs 1 and 2 at all, as the faint remains of the dividing line can be seen passing down in front of 3. What, therefore, happened was that the scribe obliterated group 4 in the wet clay, and on the space which it had occupied impressed both it and the existing signs 1 and 2 of group 5 , crowding the whole together and damaging in the process the former first sign of 5.1 It may be further remarked that, had the

1 Another alteration has been made in $\mathbf{A} 8$ by the obliteration of the last sign. Dr. Della Seta notes also that the second sign has been impressed over an obliterated sign. This is certainly correct, and the photograph seems to show that we may identify that sign as the woman $(d)$. The first sign, moreover, shows traces of an earlier sign not now identifiable (possibly one of those which the script doubtless possessed in addition to the 45 on the Disk). It has not apparently been noticed that the obliterated final sign was the "trunk with two branches" $(v)$; the general form can still be seen and even the details of the leaves on the left side. It is evident, therefore, that the whole of the group was reconstructed, which is strongly in favour of Della Seta's view that the alterations are those of the author, and not made to correct scribal errors. 
scribe been really proceeding from left to right, and discovered that space was running short, he could have gained all he wanted by setting the characters of the remaining groups somewhat closer together. If such a course had been open to him he would have certainly preferred it to the very ugly crowding which we now find in 4 and 5.

(3) Since documents are usually (not to say invariably) written in the direction in which they are intended to be read, it would seem hardly neeessary to demonstrate, as a separate proposition, that the characters are to be read from right to left, that is to say, in the order in which they are impressed. If any further argument is needed, it may be found in the fact that in Egyptian and Hittite, written like the disk with images of living things and objects, the reader proceeds in the opposite direction to that in which the characters face. Dr. Della Seta considers this a psychological necessity ; certainly, it is the way that the writers of hieroglyphs have followed.

These arguments have been generally regarded as conclusive and have been acquiesced in by, among others, M. A. J. Reinach and Prof. Macalister. But Dr. Pernier and Sir Arthur Evans, writing before the publication of Della Seta's important contribution to our understanding of the Disk, thought we should read from left to right. Dr. Pernier, however, recognised that the spiral was traced in the reverse direction, and that the analogy of Egyptian and Hittite would lead us to suppose that the characters also ran to the left.

3. Order of the Faces.-A similar, though far less important, question is, which face is to be read first, if, indeed, they are to be read continuously at all.

The indication of the faces by the letters $A$ and $B$ originated with Dr. Pernier, and has been very generally followed; but it was not based on any definite opinion as to the true order. Prof. Macalister and Sir Arthur Evans, for reasons connected with their views as to the nature of the document, proposed the reverse order. Della Seta, however, seeks to determine the question without recourse to any such opinious. He argues, very plausibly, that all writings tend to become careless towards the end; and, as Face B is obviously a less careful piece of work than Face A, he concludes that it was written after the latter.

The question is one that we can hardly hope to solve apart from the decipherment of the Disk, but there is not wanting ground for 


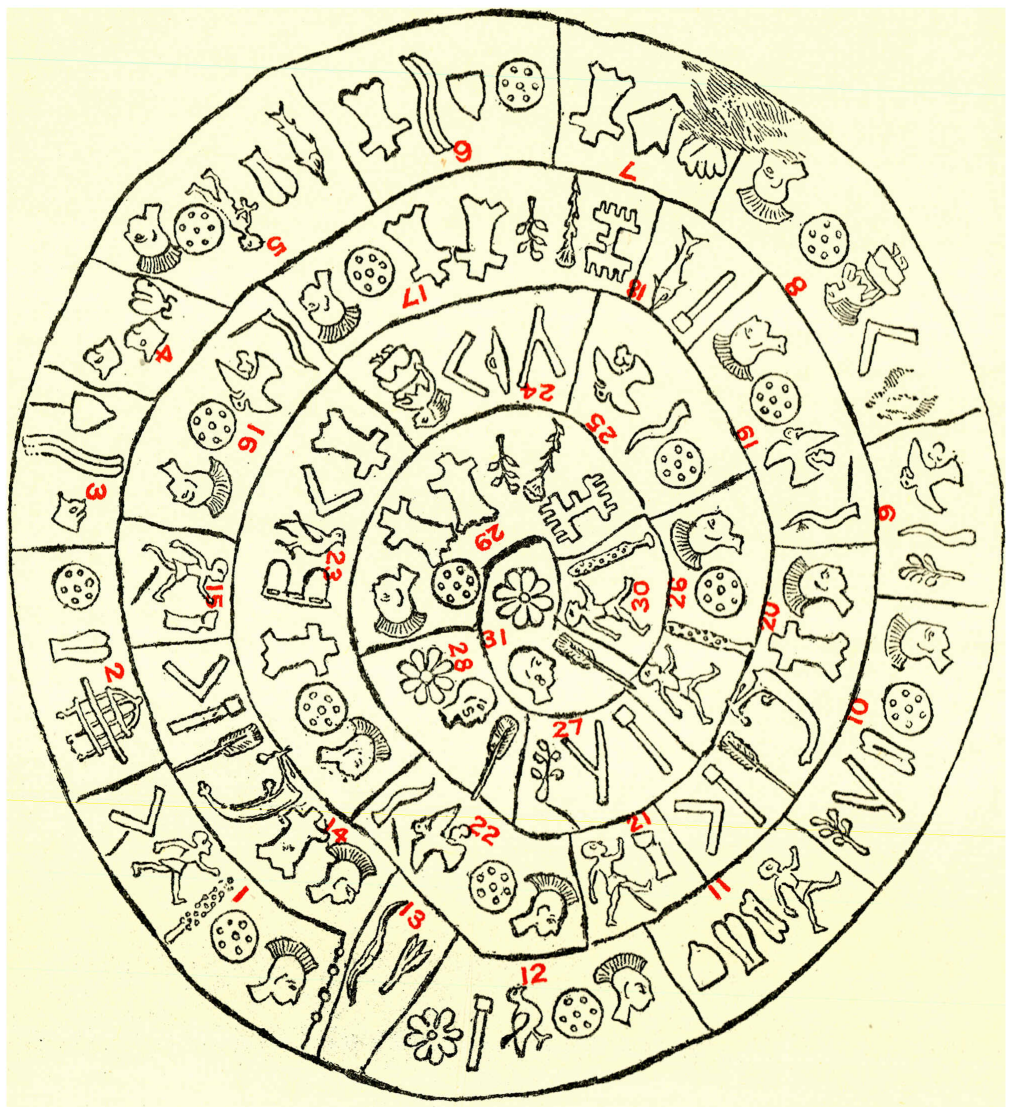

Fig. 1. The Phanstos Disk, Face A. 


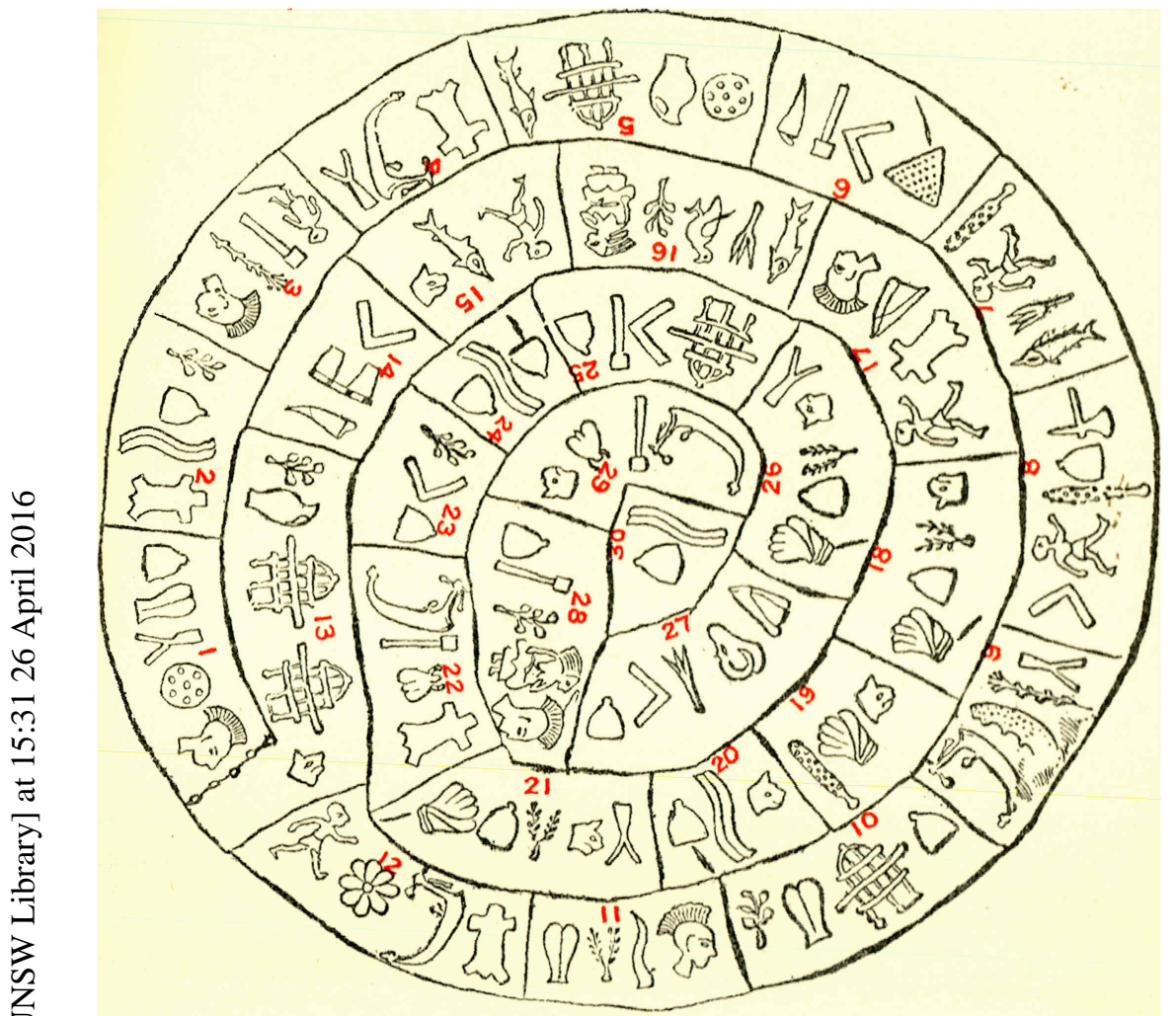

Fig. 2. The Phaestos Disk, Face B. 


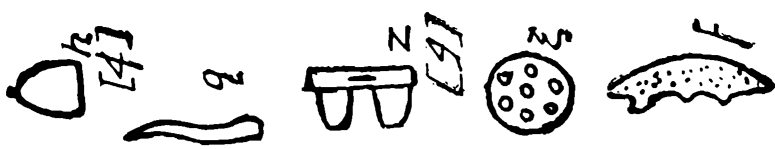

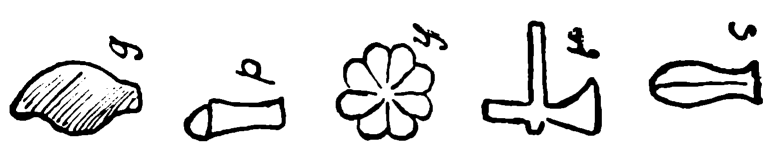

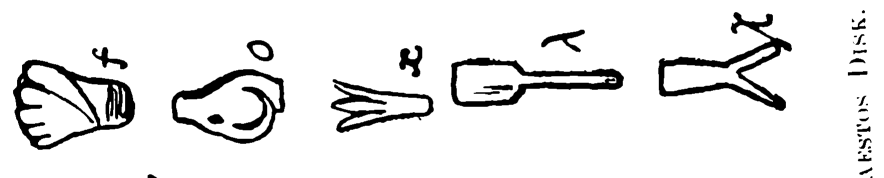

"

als?

r

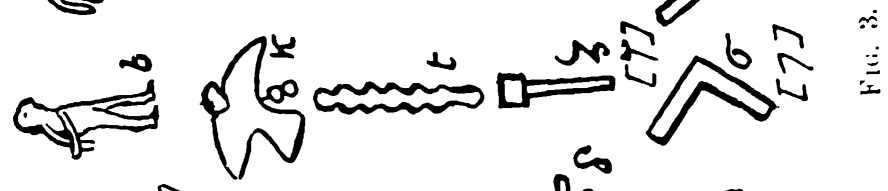

$\sum_{\rightarrow}$

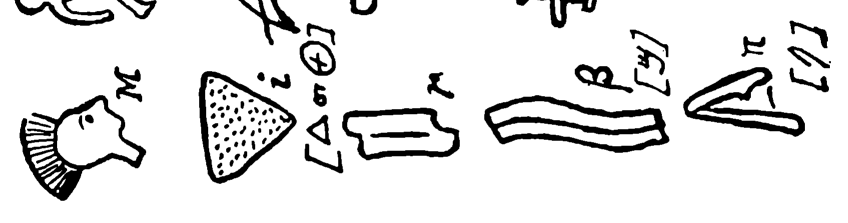


l'ernier's view that the two faces are independent texts, or at least two chapters of the same text. Unless it were necessary for each face to commence exactly as it does, it would have been easy to avoid the crowding of the signs on Face A, as compared with Face B. Della Seta also recognises that Face B may not be the continuation of Face A.

4. Position of the Signs.-A cursory examination of the Disk reveals the fact that the position of some of the signs with reference to the general line of writing varies very considerably; this is specially noticeable in the cat's head $(n)$. The important question therefore arises whether these variations have any significance, or are merely the accidental result of careless work. The point has been little discussed, but Pernier and Della Seta have arrived at opposite conclusions upon it.

As Della Seta points out, the position of the signs is governed by a fixed principle, which is that they shall occupy the least possible space in width; and subject to this principle they appear in their natural positions. The human beings, for instance, all stand on their feet but the fish stands on its tail. The natural position was also preferred in cases where only a very small space would be gained by a departure from it. Thus the sign called a "hide" (s), but which may be a coat of mail or a shirt, usually has the "arms" uppermost, but where space was specially important, as in A 29, it is reversed. The position of a sign might also be changed under special conditions, even with the result of taking up more space, as in the case of the boat in B 29. If this sign had been placed on end as usual, it would have been extremely difficult to fit in the final group. It is clear that such changes could have had no significance. But Della Seta argues that change of position had no significance in any case. $\mathbf{H} \dot{e}$ points out that it is found in identically the same groups; and we have no reason to think that the group meant one thing in the one place and another thing in the other. The groups B 21 and 26 contain the same signs, yet the cat's head $(n)$ has a different position in each; similarly in A 3 and B 20. Again, A 16, 19 and 22 are identical as to the signs, yet the flying bird or hawk $(k)$ has the natural position in 16 and 19 and is reversed in 22. From all which he argues that, even where such evidence does not exist, we ought to conclude that the differences of position are accidental.

The argument is certainly a strong one, but perhaps not altogether conclusive. It may throw some light on the matter if 
we ask ourselves why the cat's head should be the only sign to assume almost every possible position. The answer is to be found in the probable form of the punches with which the signs were impressed. It is not to be supposed that they were so made that the sign was shown on the upper side as well as on the lower; on the other hand, it is not likely that the upper side was identical for all. What we should expect would be that the general outline of the sign was visible above but not the details. If this were so, the back of the cat's head punch would be roughly square, and without close attention the scribe would not know the real position of the sign. That he could get it right when he chose is proved by B 19, 20,21, but usually he did not trouble. Let us now look at the flying bird. In this case the punch viewed from above would appear much the same whether the head were at the right hand or the left, the main difference being that the wings would be a little more to the left when the bird was in the wrong position, so that we can understand the reversal in A 22. But in A 9 and 25 the bird stands on its tail. How are we to explain this anomaly? There was no need to gain space, and in fact no space is gained; nor would any but a particularly careless man make any mistake as to the position of the punch. The inference is that the bird was made to assume this unnatural attitude of set purpose. But this is not the whole of the story. In A 16, 19 and 22 , the bird is preceded by two other signs; in A 9 and 25 it is the first sign. It would be difficult to believe that by pure accident a not very easy mistake should always be made in this special casc and in no other!

Another instance where accident seems unlikely is that of the reversed horse's hoof $(p)$ in $A^{\prime} 15$ and 21 . It is true that the position of the sign would not be easily recognised by the upper side of the punch; but this is true also of many other signs which are never out of place. This general accuracy seems to imply that special care was taken in such cases; and raises a strong presumption that the reversal of $p$, occurring as it does twice over, was deliberate.

Dr. Pernier thinks that the different positions of the signs are significant, and compares the use in Latin epigraphy of letters turned in the wrong direction to indicate the feminine. Strangely, while he mentions the bird turned upside down and the diverse 
positions of the cat's head, he does not refer to the bird standing on its tail nor to the reversed horse's hoof.

Though discussion of the objects represented by the signs has generally been excluded from this paper, that of the "breast" $(h)$ may be noticed here as being one on which the possibility of reversed signs throws light. Pernier doubtfully makes it a "cap," and A. J. Reinach says that this interpretation appears to him certain. On the other hand, it is recognised as a breast by Della Seta, Macalister, and Evans. The Egyptian sign having this meaning is almost exactly like it, except as to position; and any argument from this difference is met (as Della Seta points out) by the analogy of the reversed horse's hoof.

5. The "Virama."-The line drawn under the final signs of certain groups, and usually sloping to the right, has been explained in various ways, and most commonly as a virama; this at any rate is a convenient provisional name to denote it. It may be remarked that, owing to the difficulty of distinguishing it from the numerous cracks in the clay, different copies of the Disk have the "virama" in different places. But a careful study of Pernier's photographic reproduction removes most of the doubts. In the writer's opinion, the illustrations to this paper give all these marks accurately, except " that one should be shown under the last sign of B 8. Although: the greater part has been carried away by a breakage, the extreme end of the line can still be seen. Analogy also would lead us to expect the "virama" at this point, as the same group of three signs in A 1 has it."

The only other case that seems to require special notice is that of B 30, where some have thought to recognise another "virama." This group $(\beta h)$ occurs three times without suffix $\left(\mathrm{A}^{-3} ; \mathrm{B} 20,24\right)$, and the $h$ always take the "virama," so that we might expect one here ; and by a strange coincidence there is a line in the right position. But, as Evans remarks, it crosses the corner of the sign and it is a mere scratch quite unlike the "virama" elsewhere. Where the "virama" is present, the group $\beta h$ is always preceded by $n$ or $h$, and its occurrence may be connected with the use of these signs. Its omission in B 30 may, however, be due to this being the last group, in which case we should be led to conclude that it is a sign of pause, and therefore not required at the ond of the text.

The true virama is a mark placed under the last letter of a word written in the Devanagari alphabet to indicate that the

1 The illustration accompanying A. J. Reinach's article shows a "virama" to the left of the sign, but this mark appears from the photograph to be merely the edge of the lacuna in which the upper part of the "virama" has been lost. 
inherent vowel is elided, and the fact that the supposed virama of the Disk appears at the ends of groups only has suggested to Ed. Meyer, Hempl, Maçalister, and others that it has a similar significance. This view, however, is by no means so easy as has been thought. In the Devanagari script, the elision of inherent vowels in the body of a word is indicated either by writing the next consonant under the one whose vowel is to be elided or by a special form of the character. Now it is hardly likely that in the language of the Disk, vowels did not sometimes require to be elided otherwise than finally; and for such elision no provision appears to be made. Since we do not know what the language of the Disk was, it is of course possible that some signs stand for a simple consonant and some for the same consonant plus a vowel; but this is very improbable in such a system of writing.

Other opinions as to the use of the "virama" are : as mark of accentuation (Della Seta); as punctuation or sign of the plural (A. J. Reinach); as denoting the commencement of sentences or sections (Evans).

6. Meaning of the Text.-Of the various suggestions towards solving the enigma of the message intended to be conveyed by the author of the Disk, one of the most promising at first sight is the reading of the helmeted head $(M)$ as a determinative. To Prof. Eduard Meyer the words beginning with it are names of men, perbaps of warriors and princes; to Prof. Macalister it is a determinative of proper names, and Mr. Rowe sees in it an ideograph or determinative of "head," "chief," and the like. The reasons given for this view are that the sign in question is an appropriate one to determine personal names, and that it is unlikely that a phonetic character should occur only at the beginning of words. Attractive as the argument is, some strong reasons may be urged in opposition to it. If the groups are analysed, it will be found that those supposed to be proper names obey precisely the same laws as those which are not. The following, for instance, are strictly parallel in construction.

$\begin{array}{ccc} & \text { TABLE A. } & \\ \mathbf{1} & \mathbf{2} & \mathbf{3} \\ t a & \beta h & \\ t a x l & n \beta \underline{h} & \\ M \xi t a & h \beta \underline{h} & M \xi k q \\ M \xi t a \underline{\sigma} & s \beta h \xi & k q \underline{\xi} \\ \mu h t a \underline{\sigma} & s \beta h w & k q v\end{array}$


In all three columns we have a central group, and this group can either stand alone or be accompanied by prefixes and suffixes in various combinations. As there is no determinative in col. 2, why should we think there is in cols. 1 and 3 ? Further, we find in cols. 1 and 3 that the central groups, $t a$ and $k q$, with or without prefixes and suffixes, occur five times without determinative, and therefore presumably as ordinary words. It is by no means impossible that the same roots should appear in proper names and in ordinary words ; indeed, since all proper names are significant in origin, they must do so. But is it in the remotest degree likely that the root meaning of one proper name should require to be expressed three times, and of another proper name twice, in a short document of sixty-one words?

The table also shows that, if $M$ is a real determinative, there were two names in the same document so closely alike as $\xi$ ta and

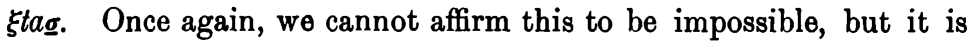
obviously far more likely that the forms are to be explained in the same way as those in col. 2. Prof. Macalister seems to have felt the difficulty, for he suggests that in one case $\sigma$ has been omitted, "by accident, or to save space"-a very dangerous hypothesis when dealing with an unknown script.

In close connection with the theory of proper names on the Disk is Prof. Macalister's view that it is a contract tablet. .If we reject the helmeted head as a determinative, there is no longer any ground for this explanation, on which also depends the order B A, A being supposed to be a list of the witnesses. An independent objection is that contract tablets usually contain numerals, and the known systems of numerals (including that of the Cretan pictographs) would lead us to expect that these would be easily distinguishable from the other words. No signs, however, can be pointed to as fulfilling this condition.

Another opinion is based mainly on arguments about the place of origin of the Disk. Pernier, on its discovery, pronounced it to be a Cretan product, but this view has been almost universally rejected. The hieroglyphs are, in the main, different from the Cretan pictographs, and some of the most usual of the latter do not appear at all. The similarity which exists in some cases is no sufficient argument for a common origin, since all hieroglyphic writing must be derived more or less from the same material. Dr. Pernier has argued that the difference of aspect may be partly 
due to the differences of technical processes; but (as Sir Arthur Evans points out) this very difference "might be regarded as itself only another indication of non-Cretan origin." On this basis A. J. Reinach has reached the conclusion that the Disk is probably the copy, preserved in the archives of Phaestos, of some convention or treaty.

Pernier and Evans both attribute a sacred character to the Disk, the former comparing it with the leaden bulla of Magliano, which contains the names of Etruscan divinities and is regarded as a ritual of the Etruscan religion. It is engraved in a spiral like the Disk, from which, however, it is separated in time by over 1,000 years. Evans, basing himself on the evidence of metrical arrangement, thinks that the Disk represents some chaunt or incantation.

The theory of a treaty of alliance or an account of a campaign is favoured by M. Dussaud. He considers that the Cretan pictographs use a lion as the emblem of royalty ; and for this reason, together with its position, he supposes $n$ (a head of a lioness in his view) to represent "king of," the following signs indicating the name of the country.

M. Ch. Bruston comes to the conclusion that the Disk contains "the list of the principal dignitaries of the island of Crete in the 17 th or 18th century before our era." A very similar view is put forward by Mr. Rowe, but with him the Disk is not Cretan but Cypriote. He suggests that the ten "names" preceded by $M \xi$ ("Chief of the Shield"), are those of the ten Cypriote princes (nine Greek and one Phœnician), who paid homage to Esarhaddon in 673 B.c. The obvious difficulty that the names on the Disk cannot be equated with those recorded in Assyrian, is met by the assumption that native names would be given to their rulers by the Cypriotes.

We may note finally that the language of the Disk has been claimed as Greek by Prof. Hempl and by Miss Stawell, and as Finnish by Arthur Gleye, while the Rev. John Griffith has argued that the text is probably a calendar.

7. Characteristics of the Writing.-The best account of these is to be found in Dr. Della.Seta's paper, in which he has fully discussed the indications which the Disk affords of the structure of the language in which it may be supposed to be written. The dominant feature which discloses itself is called by Della Seta disematism, ${ }^{1}$

1 Wo adopt this word as the equivalent of disematismo, and similarly diseme for disema. 
which is defined as "the constant and necessary union of two uigns." This is accompanied by a system of prefixes and suffixes. For example, the diseme ta occurs five times (see Table A)-once standing alone, once followed by the diseme $x l$, twice preceded by the diseme $M \xi$ (in one case with the suffix $\sigma$ ), and once preceded by the diseme $\mu h$ and followed by the suffix $\underline{\sigma}$. A similar arrangement can be traced in many other groups. From the above evidence, and from the fact that the Disk contains no group of less than two signs, it is clear that we have to do with a real law of the writing and not with fortuitous combinations, though it is, of course, possible that there may be some instances of the latter.

The disematism being established, Della Seta proceeds to consider the possible value of the signs, and, first of all, the alphabetic hypothesis, which he refutes.

On the alphabetic hypothesis the first sign of a diseme will usually be a consonant and the second a vowel, though it makes but little difference to the argument if we reverse them. According to Della Seta's analysis, there are $1 \dot{7}$ signs which occur only as prefix or first sign of a diseme, 16 which occur only as suffix or second sign of a diseme, 9 which may occur in either position, and 3 whose position is doubtful. From these figures we may conclude that some 20 signs have a vocalic value, which is far too great a number out of a total of 45 characters.

The next argument against the alphabetic hypothesis is that many of the signs occupy a fixed position in the groups. $M$ is found only at the beginning of a group ; $n$ either at the beginning of a group or as first sign of a diseme ; while $\xi$ can apparently have no other place than that following $M$ or at the end of a group. But in alphabetic writing, while certain letters may appear preferably in one position rather than another, a large measure of mobility exists. Further, the signs not only occupy determinate positions in the groups, but many of them require the accompaniment of one special character or one of two characters. For instance, $t$ is alwoays followed by $a, \beta$ by $h$, and $k$ by $q$; while $\delta$ takes either $g$ or $s$ after it. It seems in some cases also difficult for the second sign to occur apart from the first ; $q$ is found six times altogether, five times following $k$, and once only in another position (B 11) ; $g$ appears only after $\delta$. Here, again, the phenomena are quite different from those of alphabetic writing. Some consonants may, it is true, specially attract certain vowels, but it would be a strange kind of writing in which it was essential that a given letter should be followed by a certain other letter.

Dr. Della Seta next deals with the syllabic hypothesis, and finds the same objections to it as to the alphabetic. Languages are not, 
in fact, so constructed that certain syllables (any more than certain letters) must always appear at a determinate place in a word, and must always be followed by certain other syllables.

The only remaining hypothesis in Della Seta's opinion is a combination of phonetic signs and ideograms; this theory he develops at great length, but his argument can only be rapidly summarised here.

He first points out that it is not possible to make a clear division between phonetic and ideographic characters, since the former have an ideographic derivation; and he puts forward the view that those signs which are prefixes or first signs of a diseme are ideograms, those which are suffixes or second signs of a diseme are phonetic, and those which may take either position are ideographic and phonetic in turn. The question whether the phonetic part of a diseme is a partial transcription of the ideogram (like the Egyptian complementaries) or an inflexion, is a problem that at first sight seems impossible of solution. But when we consider that the same signs which are second in a diseme are sometimes suffixes to a whole group, where they cannot be the transcription of an ideogram, it is probable that they may represent the inflected part of the word (gender, number, case, person, tense, mood).

A question may be raised, says Della Seta, as to why, on his view, the ideograms should not sometimes appear alone (as in Egyptian), and this leads him to consider whether the groups separated by vertical lines are really words or are not rather groups of words. To this he answers that they are probably groups of words.

Taking the "typical example" $M \xi$, he argues that from its frequent occurrence (13 times), its conspicuous position (always first in a group), and the very nature of the principal sign (the human head), we ought to conclude that it is an essential part of the group and not a mere inflexion. Whence naturally follows its recognition as subject of the various verbs by which it is accompanied in the different groups. Admitting such a combination of two parts of speech, we must conclude that the groups are not mere words but true sentences, consisting in the smallest of the verb alone and in the largest of verb, subject, and complement. It is further argued that the groups are not separate words because no group consists of less than a diseme, while in every group a diseme is clearly recognisable, and it is not possible to believe that all the parts of speech of a language are of one single type.

The results at which Dr. Della Seta has arrived are almost wholly accepted by M. A. J. Reinach, the only important difference 
of opinion between them being as to the nature of the groups. As against Della Seta's view that they are sentences, Reinach argues that it is hardly probable that sentences should be so short as to be rendered by two signs. He thinks that the groups are the words of an agglutinative language with traces of inflexion. The prefixes and suffixes will, then, not be the subjects and objects of verbs, but will rather serve "to determine modes of existence or of action."

This last opinion is substantially that of Prof. Macalister. He considers the prefixes $\xi, s, n, h, \chi$, and the suffixes $w$ and $\xi$ to be marks of declension, and deduces the grammatical rule that words in apposition begin with the same prefix. Thus we have $n$ in A 3, 4 ; 8 in A 6, $7 ; h$ in B 23-25; and $n$ again in B 19, 20.

8. Difficulties of the Lingtistic Hypothesis.-The preceding portion of this paper has been written on the assumption that the Disk is a document in some language, and that the problem before the student is to find the nature of that language. This assumption has been regarded as unquestionable by all previous writers, and it is primâ facie the most probable one. But it has led nowhere, and it may be worth while to admit (provisionally at any rate) the possibility that, after all, the signs on the Disk do not express any language whatever.

If the Disk is, as generally believed, the sole monument we possess of an unknown language, there would seem to be only three possible views of the nature of the script. As no one is likely at the present day to repeat the error of the early "decipherers" of Egyptian, who could not conceive of obvious pictures being anything but ideograms, the script must apparently be either (1) alphabetic, (2) syllabic, or (3) a mixture of ideographic and phonetic characters. Since, for the reasons already given by Della Seta and Reinach, (1) and (2) are plainly inadmissible, it remains to enquire whether (3), which they have adopted, is any more acceptable. It is submitted that it is not, and the arguments for this opinion will be found to be very similar to those which prove the impossibility of (1) and (2).

One of these arguments is, that the ideographic nature of the first element of a diseme requires us to suppose the repetition of the same word to an incredible extent. Three of the most clearly marked disemes are $t a, \beta h$ and $k q$, and these alone would account for 16 words out of 61 , or more than one-fourth! It is true that an ideogram need not always express precisely the same idea, but, 
unless its range were very limited, the writing would be unintelligible. One of the commonest ideograms in Egyptian is the "sun," and beyond indicating that body it has practically no other meaning than the closely related "day." 1 It is theoretically possible that the various combinations formed by a diseme might stand towards each other in the same way as the English words tar, tart, star, start. This would save us from the repetition of the same word, but at the expense of another improbability, since it would be very strange if even one set of such words, quite unrelated in meaning, should occur in a short text, to say nothing of the many that would be required to explain the writing of the Disk. Moreover, this explanation is excluded by the fact that the prefixes and suffixes must, if we are indeed dealing with a language, be true formative elements because of their occurrence with different disemes, while the $s$ and $t$ of the English words have no such function. And, in any case, it would be fatal to Della Seta's theory that the groups contain complete sentences.

Another very great difficulty is that the word represented by each ideogram seems frequently to be capable of inflexion in one way only. To refer once again to the three outstanding disemes, $t a, \beta h$ and $k q, a$ is the only inflexion of $t, h$ of $\beta$, and $q$ of $k$. It is hardly possible to believe that these three words not only occur 16 times in all, but that each one is never required, except in one mood and tense! There is a further curious fact. Other things being equal, the words which occur most frequently should have the greatest number of inflexions; but the opposite is the case here. While $t$ (five times), $\beta$ (six times), and $k$ (five times) have only one inflexion each, $d$ (four times) and $\delta$ (four times) have two each. Finally, of the seven inflexions, not a single one combines with more than one of the five ideograms. Theoretically possible, perhaps, but surely most improbable $!^{2}$

As we have already seen, there are nine signs which must, if Della Seta is correct, be used both ideographically and phonetically ; and this fact constitutes another grave objection to his theory. It

1 The ideogram "sun" must, of course, not be confused with the determinative "sun," which has a very extensive use. In the latter case the word is already fully expressed phonetically before the "sun" is written at all; in the former the "sun" is the only expression of the word.

2 Exceptionally, the sign $\zeta$ enters into many combinations; this one case, however, will hardly outweigh the evidence already cited. 
is true, as he says, that there can be no clear division between ideographic and phonetic signs, because presumably every sign in a picture writing acquires its phonetic value from its meaning as an ideogram. Nevertheless, in practice, as the Egyptian system shows, signs do tend to sort themselves roughly into classes, so that, for instance, the cerastes (or snail) and the chick (or duckling) are to be met with countless thousands of times as alphabetic characters for each occurrence as ideograms. Of the nine signs refered to on the Disk, three only are used more frequently as phonetic signs than as ideograms : $a$ (10 to 1$), h$ (14 to 4 ), and $y$ (3 to 1$)$. In the other six cases the numbers are either equal for each use or less for the phonetic use than for the ideographic. Taking the total figures for the nine signs, the phonetic use occurs 41 times and the ideographic 40. In fact, for $a$ only is the proportion anything like what we might expect on Della Seta's hypothesis. Further, in a script that has both ideographic and phonetic elements; we must assume the phonetic signs to be comparatively few in number, for if any sign could stand for the sound which it has as an ideogram, the writing would be no better than a rebus. It follows from this consideration that the number of the ideographic signs in such a script must be very much greater than that of the phonetic; and it is therefore inconsistent with the probabilities of the case that out of a total of 45 characters (ideographic and phonetic together) nine, or no less than one-fifth, should be used with both a phonetic and an ideographic value.

And this argument brings us to a final objection of a somewhat different kind. It has been recognised from the first that it is not likely that the 45 signs on the Disk are the whole of those belonging to the script. Seeing that nine of these signs occur once only, it would be strange if there were not others that do not occur at all. But it may reasonably be argued that there could not have been many more, as in that case the work of cutting the punches and the difficulty of handling them would have been too great to be worth while. It would obviously have been much simpler to form each character in the clay as the Babylonians did. But a system in which 26 ideograms could be used in one short text must have possessed at least several hundreds in all !

Prof. Macalister's view of the groups as words requires to be dealt with on slightly different lines, but in substance it is open to the same objections as those already advanced against the theories of Della Seta. As has been stated, Prof. Macalister takes the prefixes and suftixes to be marks of declension, and here a serious difficulty at once 
presents itself. As Face $A$ is ex hypothesi a list of witnesses, with their titles, the whole must be in the same case. Therefore the only possible explanation of the differing prefixes is that the words belong to different declensions. There is, of course, nothing surprising in this, but it entails consequences that do not seeru easy to accept. The prefix $h$ occurs three times in succession (B 23-25), and the prefix $n$ no less than four times (B 18-21),' so that the three words must be in the same declension, and the four words must be in the same declension. This state of affairs is not impossible, but a succession of four words would be likely to show more than one declension in a language possessing more than one.

9. The Disk as a Musical Composition.-In his Scripta Minoa (1909), Sir Arthur Evans wrote as follows, at p. 291 : “The traces thus revealed of an artificial arrangement, to a certain extent identical in both halves of the inscription, lead most naturally to the conclusion that we have here to do with a metrical composition divided into two equal staves. There can be little doubt that it follows the laws of a primitive music, and it may well represent some kind of chaunt or incantation."

These sentences come astonishingly near to the theory to be now set forth, and indeed the reference to "the laws of a primitive music" might almost suggest that Sir Arthur Evans had himself adopted that theory, did not the context show that what he really had in mind was words intended to be sung to music. The present writer desires to acknowledge that without this hint he might never have arrived at what he believes to be the solution of the riddle. It was, indeed, only after a considerable time that, one day pondering the grave difficulties of the linguistic hypothesis, the thought suddenly flashed upon him that all these difficulties might be swept away by going just one step beyond Evans and supposing that the Disk gives us, not words to be sung to music, but music itself!

With this preface, let us consider the "artificial arrangement" to which Evans refers, an important part of which becomes clear if we set out the last 18 groups of Face $\mathrm{A}$ in three lines.

${ }^{1}$ It is true that in B $21 n$ is preceded by $\chi$, but this will not prevent $n$ being a prefix, as it clearly is 80 in $B$ 18, and the signs of the latter are repeated in B 21 with $\chi$ as an additional prefix. 


\section{TABLE B.}

\section{1}

14. $M s \eta \lambda \zeta \sigma$

20. $M s \eta \lambda \zeta \sigma$

26. $M \xi t a$
2

15. $p \underline{a}$

21. $p \underline{a}$

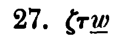

3

16. $M \xi k \underline{q}$

22. $M \xi k q$

28. $\lambda e y$
4

17. $M \xi s s w u \theta$ 18. $l \zeta$

23. $M \xi s z j \sigma s$.

29. $M \xi$ sswu $\theta$
24. $d \sigma \psi_{r}$

30. $t a$
6

19. $M \xi k q$

25. $k g \xi$

31. $\lambda e y$

On examining this table ${ }^{1}$ we see that there is a double parallelism: the three lines as a whole are parallel, and cols. 1, 2 and 3 are parallel to cols. 4,5 and 6 .

Every group in cols. 1 and 4 begins with $M$-four with $M \xi$ and two with $M s$; there being two identical groups in col. 1 and two also in col. 4. In col. 2 there are two groups of two signs and one of three, while in col. 5 there are two groups of two signs and one of four. Cols. 3 and 6 both contain the diseme $k q$ in the first and second lines, and are identical in the third line.

A very striking feature is the use of the "virama" in col. 2, where it occurs in every line. As the group $p a$ is repeated, the "virama" would naturally occur as part of it, but that the author deliberately intended there to be a "virama" in every line, is rendered certain by that in the third line being written to the sign $w$, which never has it elsewhere, though this sign occurs finally in six other places. ${ }^{2}$

Anothèr extremely remarkable fact is the way in which so many exceptional characters and groups heve been brought together in this passage, occupying less than one-third of the Disk. In cols. 2 and 5 the major part of the groups consisting of a single diseme is found, there being four here as against two in the rest of the text. The signs $e, p, \theta, \lambda$ and $\psi$, and the disemes $l \zeta$ and $\zeta \tau$ occur in this passage only; while the diseme $k q$ and the sign $\tau$ appear but once elsewhere. The unique occurrence of the "virama" under $w$ has been already mentioned.

As the last 18 groups of Face A exhibit parallelism, so also do the last 13 groups of Face B, but parallelism of a far less regular

1 Erans (p. 290) gives two figures (131 and 132) showing parallelism. Fig. 132 contains the first three columns of lines 1 and 2 of our table. Fig. 131 consists of parts of our first and third lines. This latter parallelism of four groups is perfectly good in itself, but it breaks the continuity of the passage, and, moreover, requires one group (A 16) to be used twice over.

"It is curious that the first line has the "virama" three times, the second twice, and the third once. This may be accidental, but, seeing that there are contrasts as well as resemblances in the table, it naay be part of the design. 
character. The groups again arrange themselves in three lines thus : -

TABLE C.

1

$\left.\begin{array}{ll}\text { 18. } & n v h f \\ \text { 21. } & x^{n v h f} \\ \text { 26. } & x^{n v h f} \\ \text { 27. } & \pi 0 x \sigma h \\ 28 . & \text { Mdw } h h\end{array}\right\}$
2

19. $n f t$

22. $s m \zeta \eta$

29. $n m \zeta \eta$
3

23. $h \sigma w$
4

20. $n \beta \underline{h}$

24. $h \beta \underline{h}$

30. $\beta h$

The groups do not here, as in Table B, run on without a break; but the parallelism is nevertheless unmistakable. There is even a double parallelism, but not of such an obvious kind as that on Face A. While the groups in the same column of Table B are frequently identical, here they are as a rule identical apart from their prefixes $;^{2}$ and the same-prefix extends across several columns in the present table. Thus in col. 4 we have $n \beta \underline{h}, h \beta \underline{h}$ and $\beta h$; in the second line $h \sigma w, h \beta \underline{h}$ and $h \zeta \sigma \delta$.

There is a further remarkable difference in detail combined with agreement in general plan, viz., the contrast (which it is difficult to suppose other than intentional) between the number of signs in the groups. In Table B are five groups containing six or seven signs (all in cols. 1 and 4) but not one containing five; while in Table $\mathbf{C}$ there are no less than four groups of five signs (all in col. 1), but none with six or seven. In the remaining groups of the two faces (approximately equal in number) there is no such contrast. ${ }^{3}$

These evidences of " artificial arrangement" are amply sufficient to negative any suggestion that the phenomena are merely fortuitous. We see the author planning his parallelisms, sometimes more, sometimes less, exact, like all parallelisms, as plainly as if he were expounding them to us in propria persona. And, when this is once

1 This table was originally published by Prof. Macalister, but he drew very different conclusions from it.

2 It will be understood that the word "prefix" is merely a convenient expression to denote a first sign which does not appeur to belong to a diseme.

3 We seem to have here arrived at the solution of the question of whether the two sides of the Disk are separate compositions or not. Both faces begin with a part showing no parallelism aud conclude with a part showing clear parallelism; this fact combined with the differences of detail leads to the inference that the two faces are distinct parts of one composition, so far distinct at any rate as to necessitate the slight crowding of $\mathbf{A}$ as compared with $\mathbf{B}$. 
grasped, the theory of a musical composition seems to be the only one capable of supplying a satisfactory explanation. That words intended to be set to music might naturally assume a parallelistic form is obvious, but here we have it carried to an extent that is very difficult to associate with language of any kind, and which in most languages would be hardly possible.

These 18 groups on Face $A$ and 13 on Face B, though the most striking, are by no means the only, cases of artificial arrangement. The repetition of the same sign in adjacent groups is another very marked feature of the composition.

The prefixes have already been fully considered. Omitting these and the 18 groups of Face $\mathrm{A}$, the repetitions are : $f(\mathrm{~B} \mathrm{18}, 19)$; $h(\mathrm{~B} 1,2 ; 20,21 ; 26,27) ; l(\mathrm{~B} \mathrm{15}, 16) ; r(\mathrm{~A} \mathrm{10,11)} ; w(\mathrm{~A} \mathrm{9}, 10)$; $\zeta(\mathrm{B} \mathrm{28}, 29) ; \xi(\mathrm{A} 1,2 ; 5,6)$; s (B 10,11);ta (B 7, 8). Two facts point clearly to these collocations being deliberately contrived: they consist always of two groups only, and the repeated sign never occupies the same position in both groups. The argument is strikingly confirmed by one group which we have omitted from the list. The sign $h$ really occurs in B 28, as well as in 26 and 27 . If this were added, we should have a collocation of three successive groups containing $h$, and we should also have $h$ in the same position in two adjacent groups; that is to say, the two rules would be violated at the same time. The occurrence of this particular collocation is thus marked as fortuitous.

Again, the inference seems to be clear. The author was not dealing with words, but with musical notes. Alliteration is difficult enough to accomplish successfully, but it is easy compared with the grouping of "words" of the form of those on the Disk so as to make sense. That the "words" are all quite short, and that some of the signs are rare, constitute almost insuperable difficulties from the linguistic point of view ; the most striking instance of rarity is $r$, which is found only in A 10,11 . It is significant also, that some of the commonest signs do not figure in the list at all. If we have to do with music, where the composer can, within limits, manipulate the notes as he wills, all difficulty is removed.

Certain groups consisting of a single diseme must next be considered. These are : $x \kappa, p \underline{a}, l \zeta$, and $p \underline{a}(\mathrm{~A} \mathrm{13}, 15,18,21)$. These groups present a number of very striking peculiarities: (1) They are the only disemes that always occur in isolation, the other two that once stand alone $(t a, \beta h)$ being found also in many different 
combinations. (2) The sign $\zeta$ is in every other place (10 in all) either certainly or probably the first sign of a diseme. (3) The signs $\kappa$ and $p$ do not appear elsewhere on the Disk. Such "words" present a hopeless problem on the linguistic hypothesis. As they have no prefix or suffix, they must presumably belong to some special part of speech, say conjunctions or prepositions, or both. But it would be a strange language in which unusual combinations of sound were in such a marked degree appropriated to one class of words. Again, why should all the words of this class (whatever it is) be comprised within a space of nine groups ? 1

It is almost needless to add that there can be no difficulty if the document is a piece of music. The unusually short groups and the unusual signs are there simply because the composer wanted to produce an unusual effect in that particular passage.

A final argument remains, of less weight than some others, but perhaps worth stating. It has been shown above (see p. 34) that the positions of two signs at least have been in all probability intentionally varied. These are the hawk $(k)$, which stands on its tail in A 9, 25 ; and the horse's hoof $(p)$, which is upside down in the only two places where it occurs (A 15, 21). Now, it so happens that in the oldest music hitherto known, the Greek of the third century B.c., ${ }^{2}$ this very device is actually adopted. Thus we find in the Hymns to Apollo: $V,<, x, \mho, \cup, J, \ldots .^{3}$ And, while we have this evidence of the varying positions of the signs in writing music, we know of nothing analogous in the writing of languages, as the reversed letters in Latin epigraphy are hardly parallel. If alphabets and syllabaries had been arbitrarily invented, it would have been quite easy, and certainly convenient, to select a

1 Della Seta's view, that the groups are phrases or sentences rather than words, escapes the difficulty arising from a special class of words, but does not really better the position. He regards all the single disemes as verbs. The question then has to be put: why are so many verbs that stand alone, und are spelt with unusual signs, accumulated in this small part of the Disk ?

2 Wessely has published a papyrus of the time of Augustus containing a fragment of music for a chorus of the Orestes of Euripides, which he regards as contemporary with the poot. (Revue des Etudes Grecques, vol. V (189\%), pp. 265-280.)

3 Théodore Reinach, Bulletin de Correspondance Hellénique, 1893, pp. 584-610, pll. XXI, XXI bis, XXII ; 1894, pp. 363-389, pll. XII, XII bis, XIII, XIX-XXVII. A great number of other cases are given by Alypius, edited by Meibom, Antiquæ Musicæ Auctores (1652), and now by Prof. Jan in the Teubner Series, Musici Scriptores Græci (1895). 
character for, say, $p a$, and turn it upside down for ap. But there has been surprisingly little invention in the domain of writing. Putting aside Semitic, which may or may not have followed normal processes, it seems beyond doubt that all writing has been developed out of ideograms, by using certain of the commonest and most convenient of them to express their sound, abstracted from the idea of the object depicted. Human invention, so far as we know, never went beyond this until comparatively recent times; and invented systems have not passed into current use.

With music the case is totally different, since it is impossible to get a musical notation at all without a certain amount of invention. Man has not been very lavish of his inventive labour even here; he has generally used the symbols that lay ready to his hand, and everything suggests that the signs of the Phaestos Disk were originally a syllabary. Nevertheless, there was no such connection between a sign in a syllabary and a musical note as there is between an ideogram and the name of the object depicted. Somebody had to arbitrarily decide that a certain character was to stand for a certain note, and, the inventive faculty once aroused, it found a means of economising signs by writing them in various positions. Thus it was in Greece, and thus it may well have been a thousand years earlier in Crete, or in whatever Aegean land the Disk was imported from.

\section{BIBLIOGRAPHY.}

Pernier, Dr. Luigi. Rendiconti della Reale Accademia dei Lincei, Classe di Scienze Morali, Storiche e Filologiche, Series V, vol. 17, pp. 642-651, 1908.

$$
\text { Ausonia, vol. 3, pp. 255-302 ; pll. IX-XIII, } 1909 .
$$

Della Seta, Dr. Alessandro. Rendiconti, Series V, vol. 18, pp. 297-367, pll. İ-IV, 1909.

Meyer, Prof. Eduard. Sitzungsberichte of the Berlin Academy, 1909, pp. 1022-1029.

Evans, Sir Arthur. Scripta Minoa; vol. I, pp. 22-28, 273-293, pll. XII, XIII, 1909.

Reinach, A. J. Revne Archéologique, Series IV, vol. 15, pp. 1-65, 1910.

Bruston, Ch. Bulletin de la Société Nationale des Antiquaires de France, 1910, p. 273. 


\section{BIBLIOGRAPHY-(continued).}

Hempl, Prof. George. Harper's Magazine, Jan. 1911, pp. 187-198.

Stawell, Miss F. Melian. Burlington Magazine, April, 1911, p. 23.

Griffth, Rev. John. Nature, 18 May, 1911, p. 387.

Gleye, Arthur. Kretische Studien I, 1912.

Macalister, Prof. R. A. S. Proceedings of the Royal Irish Academ!y, vol. 30, section C, pp 342-350, pl. XXXVIII, 1913.

pp. 83-87, 115-118, 128-130, 1914.

\section{The Philistines (Schweich Loctures 1911),}

Dussaud, René. Les Civilisations prehelléniques, pp. 421-437, 2nd ed., 1914.

Rowe, A. The Phaestos Disk: Its Cypriote Origin (extract from Transactions of Royal Society of South Australia, vol. 43, pp. 142-155, pll. XVI-XXII), 1919.

\section{TABLE I.}

Transcript of Face $A$.
1. M乡ta五
12. $M \xi j \zeta y$
2. $\delta s \xi$
13. $x \kappa$
22. $M \xi k q$
3. $n \beta \underline{h}$
14. $M s \eta \lambda \zeta \sigma$
23. $M \xi s z j \sigma s$
4. $n n n$
15. $p \underline{a}$
24. $d \sigma \psi \tau$
5. $M \xi b s l$
16. $M \xi k g$
6. $s \beta h \xi$
17. $M \xi s s w u \theta$
25. $k q \xi$
7. $s \phi f$
18. $l \zeta$
26. $M \xi t a$
8. $M \xi d \sigma(-)$
19. $M \xi k q$
27. $\zeta \tau \underline{w}$
9. $k q w$
20. $M s \eta \lambda \zeta \sigma$
28. $\lambda e y$
10. $M \xi ז \div v$
21. $p \underline{a}$
29. $M \xi s s w u \theta$
30. $t a$
11. $\operatorname{arsh}$
31. $\lambda e y$

Transcript of Face $B$.
1. $M \xi \times s h$
2. $s \beta h w$
3. $M u \zeta \underline{c}$
4. $\chi \eta^{8}$
5. $l \delta g \xi$
6. $\rho \zeta \sigma \underline{i}$
7. $t a x l$
8. $\mu h t a \underline{\underline{\sigma}}$
9. $\chi u F \eta$
10. $h \delta s w$

11. Mqvs

12. sฤ.ya

13. $n \delta \delta g w$

14. $\rho z \sigma$

15. nla

16. dwjxl

17. $M \pi s a$

21. $\chi n v h t$

18. nvhf

19. $n f t$

22. $s m \zeta \eta$

23. how

24. $h \beta \underline{h}$

25. $h \zeta \sigma \delta$
20. $n \beta \underline{h}$

26. $x^{n v h f}$

27. $\pi 0 x \sigma h$

28. $M d w \zeta h$

29. $n m \zeta \eta$

30. $\beta h$ 
TABLE II.

List of Individual Signs.

$M(19)$ A 1,$1 ; 5,1 ; 8,1 ; 10,1 ; 12,1 ; 14,1 ; 16,1 ; 17,1$; 19,$1 ; 20,1 ; 22,1 ; 23,1 ; 26,1 ; 29,1$. B 1,1 ; 3,$1 ; 11,1 ; 17,1 ; 28,1$.

a (11) A 1,$4 ; 11,1 ; 15,2 ; 21,2 ; 26,4 ; 30,2 . \quad$ B 7, 2 ; 8,$4 ; 12,4 ; 15,3 ; 17,4$.

b (1) A 5,3 .

c (1) B 3,4 .

d (4) A 8,$3 ; 24,1 . \quad$ B 16,$1 ; 28,2$.

(2) A 28, 2; 31, 2 .

(5) A $7,3$. B 18,$4 ; 19,2 ; 21,5 ; 26,5$.

(2) $\mathrm{B} 5,3 ; 13,4$.

$h$ (18) A 3,$3 ; 6,3 ; 11,4 . \mathrm{B} 1,5 ; 2,3 ; 8,2 ; 10,1 ; 18,3$; 20,$3 ; 21,4 ; 23,1 ; 24,1 ; 24,3 ; 25,1 ; 26,4$; 27,$5 ; 28,5 ; 30,2$

$i \quad(1)$ B 6, 4 .

$j \quad$ (3) A $\overline{12,3} ; 23,5 . \quad$ B $16,3$.

$k \quad(5)$ A 9,$1 ; 16,3 ; 19,3 ; 22,3 ; 25,1$.

$l \quad$ (6) A 5,$5 ; 18,1$. B 5,$1 ; 7,4 ; 15,2 ; 16,5$.

$m$ (3) A 4, 3. B 22, 2 ; 29, 2 .

$n$ (11) A 3,$1 ; 4,1 ; 4,2$. B 13,$1 ; 15,1 ; 18,1 ; 19,1$; 20,$1 ; 21,2 ; 26,2 ; 29,1$.

(1) $\mathrm{B} 27,2$.

(2) A 15,$1 ; 21,1$.

(6) A 9,$2 ; 16,4 ; 19,4 ; 22,4 ; 25,2$. B 11, 2.

(2) A 10,$3 ; 11,2$.

(15) A 6,$1 ; 7,1 ; 14,2 ; 17,3 ; 17,4 ; 20,2 ; 23,3 ; 23,7$; 29,$3 ; 29,4$. В 2,$1 ; 4,3 ; 12,1 ; 17,3 ; 22,1$.

(6) A 1,$3 ; 26,3 ; 30,1$. B 7,$1 ; 8,3 ; 19,3$.

(4) A 17,6 ; 29,6. B 3, 2; 9, 2 .

(4) B 11,$3 ; 18,2 ; 21,3 ; 26,3$.

w (11) A 9,$3 ; 10,5 ; 17,5 ; 27,3 ; 29,5 . \quad$ B 2,$4 ; 10,4$; 13,$5 ; 16,2 ; 23,3 ; 28,3$.

$x \quad$ (4) A $13,1 . \quad$ B 7,$3 ; 16,4 ; 27,3$.

y (4) A 12,$5 ; 28,3 ; 31,3$. B 12, 3 .

$z$ (2) A 23, 4. B 14, 2.

B (6) A 3,$2 ; 6,2 . \quad$ B 2,$2 ; 20,2 ; 24,2 ; 30,1$.

$\delta \quad(6) A 2,1.135,2 ; 10,2 ; 13,2 ; 13,3 ; 25,4$.

$\zeta$ (11) A 12,$4 ; 14,5 ; 18,2 ; 20,5 ; 27,1$, B 3, 3; 6, 2; 22,$3 ; 25,2 ; 28,4 ; 29,3$. 
TABLE II-(continued).

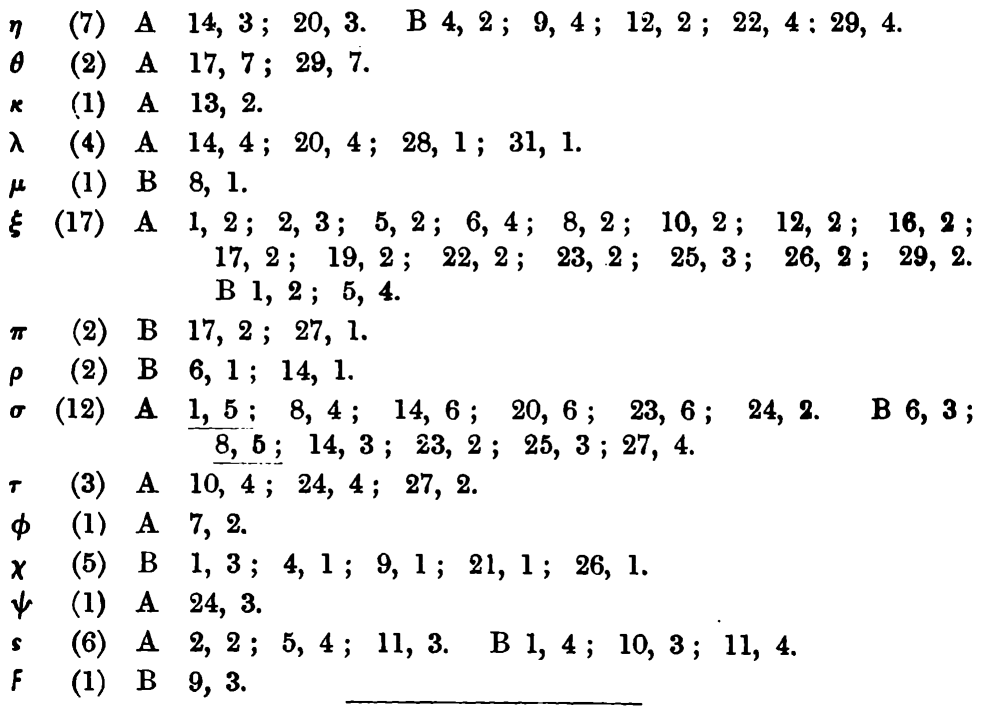

TABLE III.

List of Initial Signs.

$M$ (19) Always an initial sign.

a (1) A 11.

d (2) A 24. B 16.

$h$ (4) B $10 ; 23 ; 24 ; 25$.

$k$ (2) A $9 ; 25$.

$l$ (2) A 18. B 5 .

$n \quad(8)$ A $3 ; 4$. B $13 ; 15 ; 18 ; 19 ; 20 ; 29$.

$p \quad$ (2) A $15 ; 21$.

s (5) A 6; 7. B 2; 12; 22.

$t$ (2) A 30. B 7 .

$\begin{array}{llll}x & (1) & \text { A } & 13 .\end{array}$

B (1) B 30.

$\delta$ (1) A 2.

$\zeta$ (1) A 27.

$\lambda$ (2) A 28; 31.

$\mu \quad$ (1) B 8.

$\pi$ (1) B 27.

P (2) B $6 ; 14$.

X (4) $B \quad 4 ; 9 ; 21 ; 26$. 


\section{TABLE IV.}

\section{List of Final Signs.}

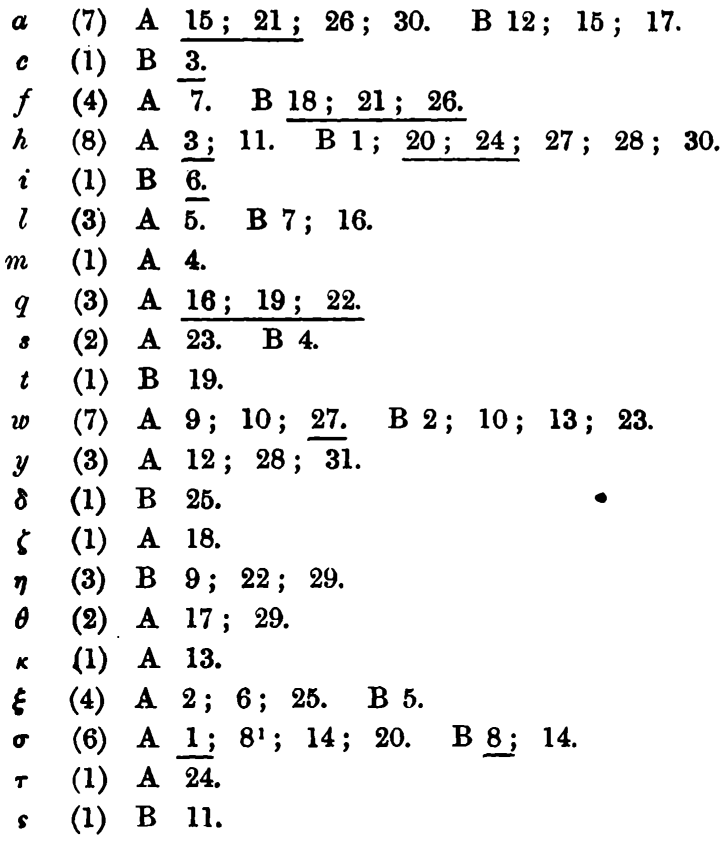

TABLE V.

List of Recurring Combinations.

$\boldsymbol{M \xi}$

A $1 ; 5 ; 8 ; 10 ; 12 ; 16 ; 17 ; 19 ; 22 ; 23$; 26 ; 29. B 1. (Always initial signs.)

$\begin{array}{lrrrrr}t a & \text { A } & 30 & & t a & \\ & \text { B } & 7 & & t a & x l \\ & \text { A } & 26 & M \xi & t a & \\ & \text { A } & 1 & M \xi & t a & \underline{\mathbf{v}} \\ & \text { B } & 8 & \mu h & t a & \underline{\sigma} \\ x l & \text { B } & 7 & t a & x l & \\ & \text { B } & 16 & d w j & x l & \end{array}$

'This sign is followed by a lacuna. 
TABLE V-(continued).

$\begin{array}{lrrrlll}d w & \text { B } & 16 & & d w & j x l \\ & \text { B } & 28 & & M & d w & \zeta h \\ d \sigma & \text { A } & 8 & & M \xi & d \sigma & (-) \\ & \text { A } & 24 & & & d \sigma & \psi \tau \\ \beta h & \text { B } & 30 & & & \beta h & \\ & \text { A } & 3 . & \text { B } 20 & n & \beta h & \\ & \text { B } & 24 & & h & \beta h & \\ & \text { A } & 6 & & s & \beta h & \xi \\ & \text { B } & 2 & & s & \beta h & w\end{array}$

$\begin{array}{llrlll}\text { os } & \mathrm{A} & 2 & & \text { os } & \xi \\ & \mathrm{B} & 10 & h & \text { is } & w\end{array}$

$\begin{array}{lll}k q & \mathbf{A} & \mathbf{9}\end{array}$

A 25

A $16 ; 19 ; 22 \quad M \xi \quad k q$

$\begin{array}{ll}k q & w \\ k q & \xi\end{array}$

$n m$

A 4

$n$

$n m$

B 29

$n m$

$\zeta$

$m \zeta \eta$

B $\quad 29$

B 22

$n \quad m \zeta \eta$

$8 m \zeta \eta$

sh

A 11

$\alpha r$

B 1

M乡x sh

$n v h f$

B 18

B $21 ; 26$

$n v \underline{\underline{f}}$

$s \eta$

B 12

A $14 ; 20$

$M$

sn

sท

$y a$
$\lambda \zeta \sigma$

$\zeta \sigma$

A $14 ; 20$

$M s \eta \lambda \quad \zeta \sigma$

B 6

B 25

$\rho \quad \zeta \sigma$

B 5

B 13

$h$

$\zeta \sigma$

$\underline{i}$

$\delta g$

$l \quad \delta g$

$n \delta \quad 8 g$

$\boldsymbol{w}$

$\tau w$

A 10

A $\quad 27$

$M \xi r \quad T w$

$\zeta \quad \underline{w}$

$n \beta \underline{h}$

A 3. B 20 M

A $17 ; 29$

$M s \eta \lambda \zeta \sigma$

A $14 ; 20$

$\lambda e y$

A $28 ; 31$

$p \underline{a}$

A $15 ; 21$

$x^{n v h f}$

R $21 ; 26$

$\cdot M \xi k q$

A $16 ; 19 ; 22$ 